\title{
Management of Liver Hydatid Cysts: A Cross- Sectional Retrospective Analysis of 293 Cases From Southern Iran
}

\section{Amirhossein Erfani}

Shiraz University of Medical Sciences

Reza shahriarirad

Shiraz University of Medical Sciences

Mehrdad Eskandarisani

Shiraz University of Medical Sciences

Mohammad Rastegarian

Shiraz University of Medical Sciences

Bahador Sarkari ( $\nabla$ sarkarib@sums.ac.ir)

Shiraz University of Medical Sciences

\section{Research Article}

Keywords: Liver hydatid cyst, Echinococcus granulosus, management, Southern Iran

Posted Date: February 24th, 2021

DOI: https://doi.org/10.21203/rs.3.rs-228712/v1

License: (9) This work is licensed under a Creative Commons Attribution 4.0 International License. Read Full License 


\section{Abstract}

Background: The current study aimed to evaluate the therapeutic features and complications of liver hydatid cyst in patients who underwent surgery for CE in Fars province, southern Iran.

Methods: A total of 293 patients who underwent surgery for liver hydatid cyst from 2004 to 2018 in Fars Province, southern Iran, were retrospectively evaluated. The clinical records of patients were reviewed and the demographic and clinical characteristics of each patient were assessed.

Results: Of the total of 293 cases, 178 (60.9\%) were females and 115 (39.1\%) were males. The mean age of the subjects was 37.22 ( \pm 20.55 ) years. The mean size of the liver hydatid cyst was $9.18( \pm 4.365)$. Of the 293 patients studied, $227(77.4 \%)$ had hydatid cysts only in the liver, while 55 (9.4\%) had both liver and lung cysts. More than half of the liver cysts $(65.9 \%)$ were located in the right portion of the liver (segment 5 to 8 ). Of the 293 cases, 52 (17.7\%) underwent radical surgery while 241 (82.3\%) underwent conservative surgery. Recurrence of hydatid cyst was recorded in $46(15 \%)$ of cases. Patients who were treated with radical surgery in comparison with those who had conservative surgery had a lower recurrence rate but a longer duration of hospital stay $(p<0.05)$.

Conclusion: Recurrence remains as one of the major challenges in the management of hydatid cyst. Radical surgery reduces the chance of recurrence, although this procedure increases the length of hospital stay.

This study was registered at Clinicaltrials.gov with registration ID of NCT04363151. https://clinicaltrials.gov/ct2/show/NCT04363151? cntry=IR\&city=Shiraz\&draw=2\&rank=1

\section{Introduction}

Cystic echinococcosis (CE) is a worldwide zoonotic parasitic disease caused by the larval stage of Echinococcus granulosus. The disease is considered to be a burden on public health in many countries, especially in temperate zones like central Asia, the Middle East, Australia, and South America (1). CE can affect almost all organs in the body but usually affects the liver (50-70\%) followed by the lungs (2-4). Sign and symptoms of liver hydatid cyst vary and depend on the location and size of the cystic structure. The cyst may be asymptomatic at the early stages of infection and become symptomatic if the cystic structure grows larger or become complicated. In symptomatic cases, it may present with abdominal pain, mostly in the right upper quadrant, jaundice, nausea, vomiting, and abnormal liver function tests.

There are several treatment options for human CE including surgical and non-surgical management, depending on the size, location and, existence of complications in the cystic structure $(5,6)$. Till about four decades ago, surgery was the only treatment for human $C E$, however in the past few years with the advent of new techniques several other treatment options have been introduced such as chemotherapy with benzimidazole and PAIR (percutaneous aspiration and injections of protoscolocidal chemicals and respiration) procedure (7-10). However, the removal of an intact hydatid cyst, if possible, remains as one 
of the best treatment options, since it usually leads to immediate and complete cure with little chance of recurrence (11). Radical treatment which is removing the whole cyst "en bloc" is considered to be the appropriate procedure for the management of liver hydatid cyst, yet simple drainage, marsupialization, capitonnage and, resection of a part of the involved organ may be used depending on the condition, size, location, and existence of complications (11).

The current study aimed to evaluate the surgical treatment and complications of liver hydatid cyst in patients who underwent surgery in two main hospitals of Shiraz, in Fars province, southern Iran, where CE is a real health challenge (12).

\section{Methods}

\section{Study area}

Fars province with the capital of Shiraz in one of the thirty-one provinces of Iran located in southwest part of the country with the population of more than 4.6 million people of which $67.6 \%$ living in urban areas, $32.2 \%$ in rural areas and $0.3 \%$ live as nomad tribes. The average temperature of Fars province is $17.8^{\circ} \mathrm{C}$, ranging between $4.7^{\circ} \mathrm{C}$ and $29.2^{\circ} \mathrm{C}$ and the annual rainfall is $261 \mathrm{~mm}$. Animal farming and agriculture are of great importance as they are considered as two main economic bases of this province. This type of livelihood has facilitated the presence of some of zoonotic diseases such as CE and toxocariasis and leishmaniasis (13-16).

\section{Data Collection}

The study has been reported in line with the STROCSS criteria (17). Hospital records of a total of 293 patients who underwent surgery for liver hydatid cyst from 2004 to 2018 in two major university-affiliated hospitals in Fars Province, southern Iran, were retrospectively evaluated. In all cases, the preliminary diagnosis of hydatid cyst has been confirmed by postoperative pathological findings. So, the inclusion criterion of operation with the diagnosis of CE was considered while reviewing the records.

Information such as age, sex, presenting signs and symptoms of hydatid cyst, number and the specific location of cystic structures, history of relapse, reoperation, characteristics of the cyst (calcification, puss discharge, multicystic, multiloculated, daughter cyst, rupture, inflammation, superimposed infection and septation), early postoperative complications, diagnostic procedures such as ultrasound scanning, computed tomography, X-rays, pathology reports, lab data, operation information and, drug therapy were extracted from the hospital records of each patient. The surgical procedure used for the patients, radical or conservative, was noted. Radical surgery is mainly defined by resecting a part or entire organ to remove the cystic structure. Subadventitial cystectomy is also considered as a radical procedure. Conservative surgery is considered as a simple, easy-to-perform procedure that aims to remove the parasitic content of the cyst, without completely removing the cystic (fibrotic) wall; such procedure is also known as a deroofing or resection of the protruding dome, sometimes associated with omentoplasty.

\section{Statistical analysis}


All data were recorded, using SPSS software, version 22 for Windows (SPSS Inc.). Statistical analysis was performed using the Chi-square Test for independence or categorical dependent variables. $p<0.05$ results were considered to be statistically significant.

\section{Results}

The total number of patients who underwent surgery with hydatid cyst between 2004 and 2018 was 293 cases. Of these, $178(60.9 \%)$ were females and $115(39.1 \%)$ were males. The mean age of the subjects was 37.22 ( \pm 20.55 ) years, ranging from 3 to 96 years. Most cases $(31.4 \%)$ were in the age group of 50 years and older. Of 293 patients, $126(43 \%)$ presented with abdominal pain, $26(8.9 \%)$ with nausea, $21(7.2 \%)$ with vomiting, 8 (2.7\%) with weight loss, 23 (10\%) with anorexia, 35 (15.4\%) with fever, 9 (4\%) with chills, $16(7 \%)$ with dyspnea and $20(8.9 \%)$ with cough. On examination $9(4 \%)$ had tenderness, 11 $(4.8 \%)$ reported mass sensation on palpation and $5(1.7 \%)$ had organomegally. Imaging results showed that liver hydatid cyst was detected in 138 out of 139 (99.3\%) by abdominal CT scans, and also detected in 187 among 189 (98.9\%) by abdominal ultrasound imaging. Among the 293 cases, 170 (67.5\%) cases had a single cyst, $52(20.6 \%)$ had 2 cysts, and $30(11.9 \%)$ had 3 or more cysts. Of the 293 patients studied, 227 (77.4\%) had hydatid cysts only in the liver, while 55 (9.4\%) had both liver and lung cysts, and $11(1.9 \%)$ had liver and other organs (but not lung) cysts. It is worth mentioning that there was a significant association between having the hydatid cyst in the liver and lung $(p<0.05)$ but not between the liver and other locations $(p>0.05)$. More than half of the liver cysts $(65.9 \%)$ were located in the right portion of the liver (segment 5 to 8 ) while $82(28 \%)$ of them were located in the left lobe (segment 1 to 4 ). Figure 1 shows the percentage of infection with hydatid cyst in various liver segments and Table 1 shows the frequency and correlation of hydatid cyst in different segments of liver lobes. 
Table 1

The frequency and correlation of hydatid cyst in different segments of liver lobes

\begin{tabular}{|c|c|c|c|c|c|c|c|c|}
\hline & Seg. 1 & Seg. 2 & Seg. 3 & Seg. 4 & Seg. 5 & Seg. 6 & Seg. 7 & Seg. 8 \\
\hline $\begin{array}{l}\text { Seg. } \\
1\end{array}$ & $\begin{array}{l}1 \\
(0.3 \%)\end{array}$ & $0(0 \%)$ & $0(0 \%)$ & $0(0 \%)$ & $0(0 \%)$ & $0(0 \%)$ & $0(0 \%)$ & $0(0 \%)$ \\
\hline $\begin{array}{l}\text { Seg. } \\
2\end{array}$ & $0(0 \%)$ & $5(1.7 \%)$ & $\begin{array}{l}2(0.7 \%, \\
P= \\
0.005)\end{array}$ & $0(0 \%)$ & $0(0 \%)$ & $\begin{array}{l}1(0.3 \%, \\
P= \\
0.568)\end{array}$ & $0(0 \%)$ & $0(0 \%)$ \\
\hline $\begin{array}{l}\text { Seg. } \\
3\end{array}$ & $0(0 \%)$ & $\begin{array}{l}2(0.7 \%, \\
P= \\
0.005)\end{array}$ & $7(2.4 \%)$ & $\begin{array}{l}1(0.3 \%, \\
P= \\
0.328)\end{array}$ & $\begin{array}{l}1(0.3 \%, \\
P= \\
0.345)\end{array}$ & $\begin{array}{l}1(0.3 \% \\
P=1.00)\end{array}$ & $\begin{array}{l}1(0.3 \% \\
P=1.00)\end{array}$ & $\begin{array}{l}1(0.3 \%, \\
p= \\
0.439)\end{array}$ \\
\hline $\begin{array}{l}\text { Seg. } \\
4\end{array}$ & $0(0 \%)$ & $0(0 \%)$ & $\begin{array}{l}1(0.3 \% \\
P= \\
0.328)\end{array}$ & $\begin{array}{l}16 \\
(5.5 \%)\end{array}$ & $\begin{array}{l}3(1.0 \%, \\
p= \\
0.057)\end{array}$ & $\begin{array}{l}3(1.0 \% \\
p= \\
0.720)\end{array}$ & $\begin{array}{l}3(1.0 \% \\
p= \\
0.466)\end{array}$ & $\begin{array}{l}2(0.7 \%, \\
P= \\
0.363)\end{array}$ \\
\hline $\begin{array}{l}\text { Seg. } \\
5\end{array}$ & $0(0 \%)$ & $0(0 \%)$ & $\begin{array}{l}1(0.3 \% \\
P= \\
0.345)\end{array}$ & $\begin{array}{l}3(1.0 \%, \\
p= \\
0.057)\end{array}$ & $\begin{array}{l}17 \\
(5.8 \%)\end{array}$ & $\begin{array}{l}9(3.1 \%, \\
p= \\
0.000)\end{array}$ & $\begin{array}{l}3(1.0 \% \\
P= \\
0.713)\end{array}$ & $\begin{array}{l}6(2.0 \%, \\
P= \\
0.001)\end{array}$ \\
\hline $\begin{array}{l}\text { Seg. } \\
6\end{array}$ & $0(0 \%)$ & $\begin{array}{l}1(0.3 \% \\
P= \\
0.568)\end{array}$ & $\begin{array}{l}1(0.3 \% \\
P=1.00)\end{array}$ & $\begin{array}{l}3(1.0 \%, \\
p= \\
0.720)\end{array}$ & $\begin{array}{l}9(3.1 \%, \\
p= \\
0.000)\end{array}$ & $\begin{array}{l}45 \\
(15.4 \%)\end{array}$ & $\begin{array}{l}27(8.5 \%, \\
P= \\
0.000)\end{array}$ & $\begin{array}{l}7(2.4 \%, \\
P= \\
0.063)\end{array}$ \\
\hline $\begin{array}{l}\text { Seg. } \\
7\end{array}$ & $0(0 \%)$ & $0(0 \%)$ & $\begin{array}{l}1(0.3 \% \\
P=1.00)\end{array}$ & $\begin{array}{l}3(1.0 \%, \\
p= \\
0.466)\end{array}$ & $\begin{array}{l}3(1.0 \% \\
P= \\
0.713)\end{array}$ & $\begin{array}{l}27(8.5 \%, \\
P= \\
0.000)\end{array}$ & $\begin{array}{l}40 \\
(13.7 \%)\end{array}$ & $\begin{array}{l}8(2.7 \%, \\
P= \\
0.006))\end{array}$ \\
\hline $\begin{array}{l}\text { Seg. } \\
8\end{array}$ & $0(0 \%)$ & $0(0 \%)$ & $\begin{array}{l}1(0.3 \%, \\
p= \\
0.439)\end{array}$ & $\begin{array}{l}2(0.7 \%, \\
P= \\
0.363)\end{array}$ & $\begin{array}{l}6(2.0 \%, \\
P= \\
0.001)\end{array}$ & $\begin{array}{l}7(2.4 \%, \\
P= \\
0.063)\end{array}$ & $\begin{array}{l}8(2.7 \%, \\
P= \\
0.006)\end{array}$ & $\begin{array}{l}23 \\
(7.8 \%)\end{array}$ \\
\hline
\end{tabular}

The size of liver hydatid cyst ranged from 1 to $26 \mathrm{~cm}$ (mean: 9.18, SD = 4.365). Most of the cysts (50.6\%) were between 6 to $10 \mathrm{~cm}$, and the least cases $(7.5 \%)$ were above $15 \mathrm{~cm}$. The area of square meters of the liver cysts ranged from 1 to $393 \mathrm{~cm}^{2}$ (mean $=60.41, \mathrm{SD}=54.259$ ) with the highest frequency $(31 \%)$ in less than $26 \mathrm{~cm}^{2}$ and the least (13.5\%) in 51 to $75 \mathrm{~cm}^{2}$ group.

Of the 293 cases, 52 (17.7\%) underwent radical surgery while 241 (82.3\%) underwent conservative surgery. Patients who were treated with radical surgery method had a lower recurrence rate $(23.7 \%$ versus $76.3 \%$ for conservative surgery) but longer duration of hospital stay ( 8.14 versus 10.82 days).

The mean duration of hospital stay for patients was $8.62( \pm 7.97)$ days with the highest frequency in less than 5 days ( 127 cases; $45.2 \%$ ) and the least frequency for 31 days and above ( 5 cases; $1.8 \%$ ). The mean hospital stay of the patients who underwent conservative or radical surgery was 8.14 and 10.82 days, respectively. There was a statistically significant association between the type of surgery and length of hospital stay $(p<0.05)$. 
Of the 293 liver hydatid cysts, 35 (11.9\%) were calcified, 27 (9.2\%) had daughter cysts, 9 (3.1\%) were ruptured, 3 (1\%) had puss discharge, 3 (1\%) were multicystic, and 21 (7.2\%) were multiloculated. Also 4 $(1.4 \%)$ had fibrosis, $4(1.4 \%)$ had inflammation, $14(4.8 \%)$ had superimposed infection, and $9(3.1 \%)$ had septation.

In terms of medical laboratory data, $51.9 \%$ of patients had leukocytosis on admission in which $63.3 \% \mathrm{had}$ neutrophilia, $1.7 \%$ had lymphocytosis, and $62.5 \%$ with eosinophilia and $11.8 \%$ had monocytosis. A high prothrombin time (PT) level was recorded in $16.3 \%$ and a high partial thromboplastin time (PTT) level was recorded in $13.9 \%$ of patients. Elevated Alanine Transaminase (ALT) was reported in $24.5 \%$, elevated Aspartate Aminotransferase (AST) in $26.2 \%$ and high levels of Alkaline Phosphatase ALKP in $10.7 \%$ of cases. A high level of total bilirubin was recorded in $15.2 \%$, high levels of direct bilirubin in $14.6 \%$, and low levels of the album in $9.2 \%$ of the cases.

Regarding the drug treatments, various combined medications were used during hospitalization. Anthelmintic drugs (albendazole) have been used in $55.3 \%$ of cases. Other medication were including third-generation cephalosporins (64.5\%), fluoroquinolones (24.6\%), first-generation cephalosporin (24.6\%), lincosamide (16.7\%), aminoglycosides (3.8\%), Glycopeptides (1.7\%), $\beta$-lactam (1.7\%), carbapenem (1.7\%), second generation cephalosporin $(0.3 \%)$ and sulfonamides $(0.3 \%)$.

Recurrence of hydatid cyst was recorded in $46(15 \%)$ of cases, of which $32(10 \%)$ occurred once, twice in $4(0.01 \%)$ cases, and three times in $2(0.006 \%)$ cases. In patients with recurrent disease, $23.7 \%$ had undergone radical surgery while $76.3 \%$ had conservative surgery treatment. It should be noted that, based on the information which were available in the patients' records, it was not clear whether the recurrence of the disease was due to the cavity-related complications or re-activity of the parasite. Accordingly, the actual recurrence rate associated with parasite reactivation may be less than the rate stated here.

\section{Discussion}

Hydatid cysts remain a major health challenge in many countries of the world, including Iran $(12,18,19)$. In this study, the clinico-hematological and therapeutic features of hydatid cyst cases admitted to university-affiliated hospitals, from 2004 to 2018, in Fars province, southern Iran was reviewed.

Based on our findings, abdominal pain followed by fever, anorexia, nausea, and vomiting were the most common symptoms of patients before admission. Other studies reported almost the same results with abdominal pain being the most common symptom of liver hydatid cyst (20-22). Motie et al. reported that patients with liver hydatid cyst presented with abdominal pain followed by fever in most cases (23). In their study organomegaly and palpable mass were considered as the most common finding in physical examination, while in our study the most common finding in the examination was abdominal tenderness (23).

As liver $\mathrm{CE}$ is a chronic disease and symptoms would show up when the cystic structure becomes large enough to be complicated or pushes the adjacent organs, patients usually do not develop the acute 
symptoms. In this study, most of the patients had symptoms more than 90 days before the admission which is similar to the findings of Tagliacozzo et al., study in Italy which reported duration of symptoms of 2 up to 72 months (mean 16 months) for patients with liver CE before the admission to the hospital (20).

The establishment of the correct diagnosis of hepatic hydatid cyst is essential before the operation and is based upon clinical, radiological and laboratory data. Differential diagnosis relies greatly on imaging techniques such as ultrasonography, X-rays and computed tomography scans. Ultrasonography is considered to be the gold standard method for diagnosis of the disease while the CT scan is often used in emergency presentations (4). In a study by Prousalidis and colleagues, the liver hydatid cyst was found in $92 \%$ and $95 \%$ of the ultra-sonographies and CT scans which is in line with our findings (24). In Prousalidis et al., study leukocytosis was found in all cases and hypereosinophilia in $14.3 \%$ of them while in our study, almost half of the patients had leukocytosis and more than half of them had hypereosinophilia (24).

New procedures have been used in recent years for the management of hydatid cyst including total cystectomy and percutaneous and perendoscopic procedures, which improved the treatment efficacy as well as the quality of life of CE patients (23). Management of liver hydatid cysts includes percutaneous sterilization practices, surgery, drug treatment, a 'watch-and-wait' approach or a combination of these (24). In our study, most of the cases (82.3\%) underwent conservative surgery. Patients who were treated with radical surgery method had a lower recurrence rate but longer duration of hospital stay. Motie et al., and Gomez et al., recommended the radical surgery treatment because of the shorter length of hospital stay and its lower rate of complications and recurrence $(25,26)$. Tagliacozzo and collogues reported that although radical surgery can reduce the rate of complications, recurrence and hospital stay, performing a radical surgery must be done only in an exceptional case to avoid removing healthy hepatic parenchyma (20).

The effectiveness of radical treatment in comparison with conservative treatment has been documented in several studies. In Georiou et al., study the therapeutic features of 232 patients who underwent surgery for liver hydatid disease was evaluated. Those patients who underwent a radical procedure had no mortality and no recurrence and a low rate $(10.95 \%)$ of morbidity. Those patients who treated with conservative method had a mortality rate of $2.76 \%$ and morbidity of $24.13 \%$ and $6.9 \%$ of relapse at threeyear complete follow-up. The authors concluded that radical surgical treatment are better tolerated by patients and yielded better results in terms of mortality and the rate of recurrence (27). In Secchi et al., study in Argentina, a relatively large group of CE patients (1412) with radical, or conservative surgical procedures have been evaluated. The complication rate has been significantly lower in patients with radical surgery compared with the other procedures. Moreover, the rate of reoperation and recurrence has been significantly lower in patients with radical surgery treatment (28).

Biliary spillage is the foremost common cause of postoperative morbidity after conservative liver CE surgery. In Surmelioglu et al. study, postoperative leakage was detected in 36 out of 186 (19.4\%) patients 
with solitary liver hydatid cyst with conservative surgery (27). While conservative surgery with omentoplasty is reducing the postoperative complications, radical surgery along with administration of albendazole has been considered as the best management option for liver hydatid cysts owing to its low complication and recurrence (29).

Recurrence remains one of the main complications in the management of hydatid disease. In the current study, recurrence of hydatid cyst was recorded in $15 \%$ of cases, of which $10 \%$ occurred once, $0.01 \%$ and $0.006 \%$ ) cases occurred twice and three times, respectively. In the recurrence cases, $23.7 \%$ had been treated with radical surgery while $76.3 \%$ with conservative surgery. In another study by the authors in Yasuj district in southwest of Iran, recurrence has been reported in $14 \%$ of hydatid cysts (19). In Spain, among the 217 patients with liver hydatid cyst, 25 (11.5\%) had a hydatid recurrence after curative treatment. (30).

Anthelmintic drugs (mostly albendazole) are the drug of choice which are often used in liver CE and it appears to have greater efficacy $(20-60 \%)$ for shrinkage or disappearing the cystic structure than any other agent used so far $(31,32)$. In a systematic review and meta-analysis, Gomez et al. reported that anthelmintic drugs alone are not considered as ideal treatment for hydatid cyst of the liver (26). In our study, the main drugs that have been used were albendazole and third-generation cephalosporins. The use of third-generation cephalosporin (especially ceftriaxone) is because of their prophylactic effects, after the surgery, for the prevention of wound infection and complications.

Given the nature of any retrospective study, our study also had shortcomings. These limitations included some missing data and the inability to follow up the patients.

\section{Conclusion}

Hydatid cyst, especially liver disease, as the most common form of the disease, is still a significant health problem in Iran. Despite advances in the treatment of liver hydatid cysts, there are several challenges exist including choosing the appropriate surgical procedure based on the individual patient's condition. Recurrence remains as one of the major challenges in the management of this disease. Radical surgery reduces the chance of recurrence, yet increasing the length of hospital stay.

\section{Declarations}

\section{Ethical statement}

The study was approved by the Ethics Committee of the Shiraz University of Medical Sciences and conducted in compliance with local regulatory requirements, Good Clinical Practice (GCP), and the Declaration of Helsinki. The patients' records were anonymized and de-identified prior to analysis. The confidentiality of the details of the subjects was assured. Written informed consent was obtained from all patients or their legally authorized representatives. 


\section{Consent for publication}

Not applicable.

\section{Available data and materials all materials}

The datasets used and/or analysed during the current study available from the corresponding author on reasonable request.

\section{Conflict of interest}

The authors declare that they have no competing interests.

\section{Funding}

No funding source was used for this study.

\section{Authors' contributions}

RS and $B S$ designed the study, RS, AE, ME and MR collected the data. BS, RS and AE were major contributors in writing the manuscript and analyzed the data. All authors have read and approved the submitted manuscript.

\section{Acknowledgment}

The technical assistant of staff in Nemazi and Faghihi hospitals is acknowledged.

\section{References}

1. Grosso G, Gruttadauria S, Biondi A, Marventano S, Mistretta AJWjogW. Worldwide epidemiology of liver hydatidosis including the Mediterranean area. World J Gastroenterol.2012;18:1425.

2. Wen H, Vuitton L, Tuxun T, et al. Echinococcosis: Advances in the 21st Century. Clin Microbiol Rev. 2019;32(2).

3. Sokouti M, Sadeghi R, Pashazadeh S, et al. A systematic review and meta-analysis on the treatment of liver hydatid cyst: Comparing laparoscopic and open surgeries. Arab J Gastroenterol.. 2017;18:127-135.

4. Keong B, Wilkie B, Sutherland T, Fox A. Hepatic cystic echinococcosis in Australia: an update on diagnosis and management. ANZ J Surg.. 2018;88:26-31.

5. Sayek I, Yalin R, Sanaç YJAoS. Surgical treatment of hydatid disease of the liver. Arch Surg.1980;115:847-850.

6. Oral A, Yigiter M, Yildiz A, et al. Diagnosis and management of hydatid liver disease in children: a report of 156 patients with hydatid disease. J Pediatr Surg.. 2012;47:528-534. 
7. Pelaez V, Kugler C, Correa D, et al. PAIR as percutaneous treatment of hydatid liver cysts. Acta Trop.2000;75:197-202.

8. Franchi C, Di Vico B, Teggi AJCID. Long-term evaluation of patients with hydatidosis treated with benzimidazole carbamates. Clin Infect Dis. 1999;29:304-309.

9. El-On JJAt. Benzimidazole treatment of cystic echinococcosis. Acta Trop 2003;85:243-252.

10. Saidi F, Habibzadeh F. The Non-operative Management of Asymptomatic Liver Hydatids: Ending Echinococcophobia. J Gastrointest. Surg. 2018;22:486-495.

11. Moro P, Schantz PMJljold. Echinococcosis: a review. Int J Infect Dis 2009;13:125-133.

12. Sarkari B, Hosseini F, Khabisi SA, Sedaghat F. Seroprevalence of cystic echinococcosis in blood donors in Fars province, southern Iran. Parasite Epidemiol Control. 2016; 2:8-12..

13. Layegh Gigloo A, Sarkari B, Rezaei Z, Hatam GR, Davami MH. Asymptomatic Leishmania Infected Children: A Seroprevalence and Molecular Survey in a Rural Area of Fars Province, Southern Iran. J Trop Med. 2018;2018:8167247.

14. Sarkari B, Alirezaei R, Layegh Gigloo A, et al. Seroprevalence and risk factors for Toxocara infection among children in a rural community in Fars province, southern Iran. Parasite Immunol. 2018;40:e12582.

15. Sarkari B, Naraki T, Ghatee MA, Abdolahi Khabisi S, Davami MH. Visceral Leishmaniasis in Southwestern Iran: A Retrospective Clinico-Hematological Analysis of 380 Consecutive Hospitalized Cases (1999-2014). PLoS One. 2016;11(3):e0150406.

16. Sadjjadi SM. Present situation of echinococcosis in the Middle East and Arabic North Africa. Parasitol Int. 2006;55 Suppl:S197-202.

17. Agha R, Abdall-Razak A, Crossley E, Dowlut N, losifidis C, Mathew G. STROCSS 2019 Guideline: Strengthening the reporting of cohort studies in surgery. Int J Surg. 2019;72:156-165.

18. Deplazes P, Rinaldi L, Alvarez Rojas CA, et al. Global Distribution of Alveolar and Cystic Echinococcosis. Adv Parasitol. 2017;95:315-493.

19. Sarkari B, Sadjjadi SM, Beheshtian MM, Aghaee M, Sedaghat F. Human cystic echinococcosis in Yasuj District in Southwest of Iran: an epidemiological study of seroprevalence and surgical cases over a ten-year period. Zoonoses Public Health. 2010;57:146-150.

20. Tagliacozzo S, Miccini M, Bonapasta SA, Gregori M, Tocchi AJTAjos. Surgical treatment of hydatid disease of the liver: 25 years of experience. Am J Surg. 2011;201:797-804.

21. Secchi MA, Pettinari R, Mercapide $C$, et al. Surgical management of liver hydatidosis: a multicentre series of 1412 patients. Liver Int. 2010;30:85-93.

22. Martel G, Ismail S, Begin A, Vandenbroucke-Menu F, Lapointe R. Surgical management of symptomatic hydatid liver disease: experience from a Western centre. Can J Surg.. 2014;57:320-326.

23. Motie MR, Ghaemi M, Aliakbarian M, Saremi E. Study of the Radical vs. Conservative Surgical Treatment of the Hepatic Hydatid Cyst: A 10-Year Experience. Indian J Surg. 2010;72:448-452. 
24. Prousalidis J, Kosmidis C, Anthimidis G, Fachantidis E, Harlaftis N, Aletras H. Forty-four years' experience (1963-2006) in the management of primarily infected hydatid cyst of the liver. HPB. 2008;10:18-24.

25. Motie MR, Ghaemi M, Aliakbarian M, Saremi EJIJoS. Study of the radical vs. conservative surgical treatment of the hepatic hydatid cyst: a 10-year experience. Indian J Surg.2010;72(6):448-452.

26. Gomez IGC, Lopez-Andujar R, Belda Ibanez T, et al. Review of the treatment of liver hydatid cysts. World J Gastroenterol. 2015;21:124-131.

27. Georgiou GK, Lianos GD, Lazaros A, et al. Surgical management of hydatid liver disease. Int. J Sur.. 2015;20:118-122.

28. Secchi MA, Pettinari R, Mercapide C, et al. Surgical management of liver hydatidosis: a multicentre series of 1412 patients. Liver Int. 2010;30:85-93.

29. i Gavara CG, López-Andújar R, Ibáñez TB, et al. Review of the treatment of liver hydatid cysts. World J Gastroenterol. 2015;21:124.

30. Velasco-Tirado V, Romero-Alegría Á, Belhassen-García M, et al. Recurrence of cystic echinococcosis in an endemic area: a retrospective study. BMC Infect Dis. . 2017;17:455.

31. Saimot AGJWjos. Medical treatment of liver hydatidosis. World J Surg 2001;25:15.

32. Moore J, Gupta V, Ahmed MY, Gociman B. Hydatid cyst disease: optimal management of complex liver involvement. South Med J. 2011;104:222-224.

\section{Figures}




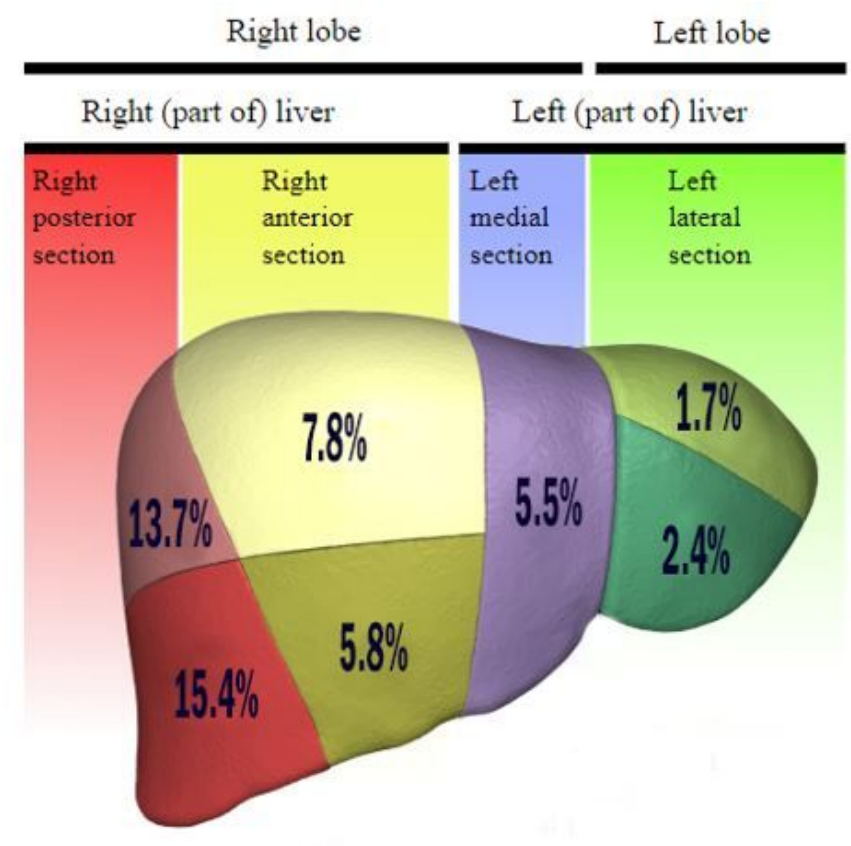

Anterior view

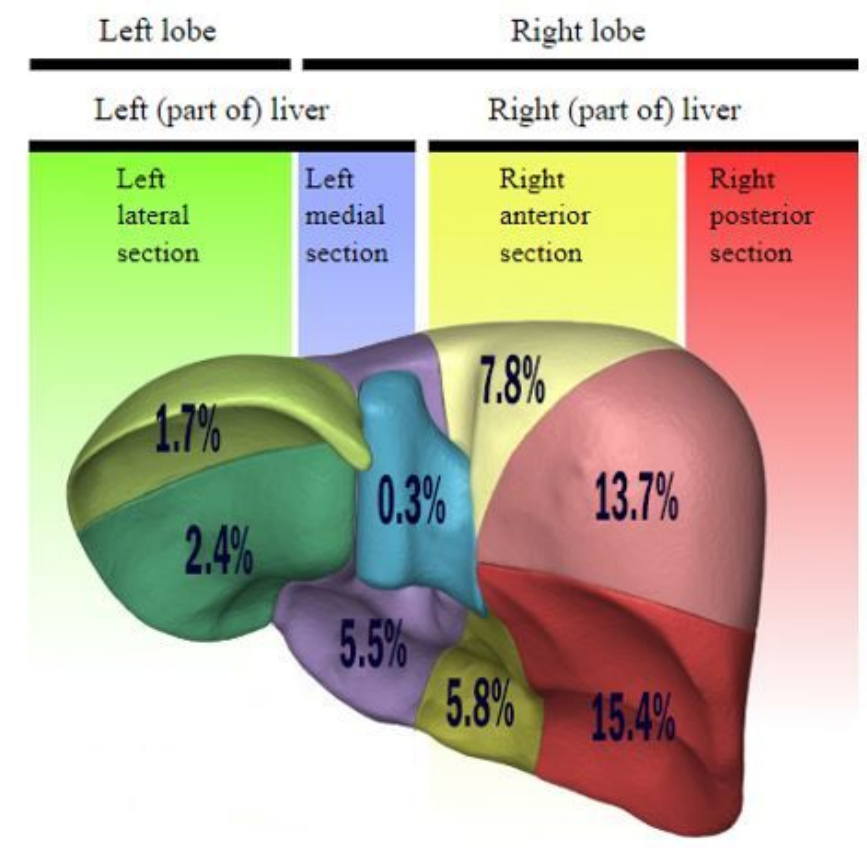

Posterior view

\section{Figure 1}

Rate of hydatid cyst infection (percent) in different segments of the liver 